\title{
SIMULASI NUMERIK II : DISTRIBUSI DIAMETER DROPLET PADA SEMPROTAN BIODIESEL KELAPA, JATROPA CURCAS DAN MINYAK GORENG BEKAS DALAM RUANG BAKAR MEXICAN HAT
}

\author{
I Gede Teddy Prananda Surya \\ Teknik Mesin Universitas Udayana \\ Jl. Raya Kampus UNUD, Kampus Bukit Jimbaran, Jimbaran \\ Kabupaten Badung, Bali, Indonesia \\ teddyps@ymail.com
}

\begin{abstract}
Abstrak
Biodiesel merupakan bahan bakar terbarukan dengan properties hampir menyerupai diesel fuel dan dapat digunakan pada motor diesel direct injection tanpa perubahan sistem bahan bakarnya. Bahan baku biodiesel yang tersedia di Indonesia antara lain kelapa, jatropa curcas dan minyak goreng bekas dapat diubah menjadi biodiesel melalui proses esterifikasi. Penelitian numerik menggunakan FLUENT 6.2 ini dilakukan pada model ruang bakar mexican hat untuk mengetahui distribusi ukuran droplet serta visualisasi semprotan dari ketiga jenis biodiesel tersebut. Pemodelan turbulen yang digunakan adalah RNG k- $\varepsilon$ karena dapat memprediksi struktur large scale yang diproduksi oleh semprotan dan squish flow sedangkan pemodelan break-up menggunakan WAVE karena semprotan ini berlangsung dalam angka Weber yang tinggi. Hasil numerik membuktikan bahwa biodiesel minyak goreng bekas memiliki droplet berdiameter lebih besar daripada biodiesel kelapa atau jatropa curcas karena memiliki tegangan permukaan tinggi. Diameter partikel akan berkurang saat penetrasi semakin jauh karena pengaruh gaya aerodinamik yang bekerja pada droplet dan droplet tadi pecah setelah bertumbukan dengan dinding piston.
\end{abstract}

Kata kunci : diameter droplet, SMD, biodiesel

\begin{abstract}
Abstrak
Biodiesel is a renewable fuel with almost changeable properties for diesel fuel and can be used in direct injection diesel motors without changing the fuel system. The raw materials for biodiesel available in Indonesia include coconut, jatropa curcas and used cooking oil that can be converted into biodiesel through an esterification process. This numerical study using FLUENT 6.2 was carried out on the Mexican hat combustion chamber model to see the droplet size distribution as well as to visualize the spray of the three types of biodiesel. The turbulent modeling used is $R N G k$ - $\varepsilon$ because it can predict large-scale structures produced by spray and squish flow while break-up modeling uses WAVE because this spray takes place in high Weber numbers. The numerical results prove that used cooking oil biodiesel has larger diameter droplets than coconut or jatropha biodiesel because it has a high surface tension. The particle diameter will decrease as the penetration gets stronger due to the influence of the aerodynamic force acting on the droplet and the droplet breaks after colliding with the piston wall.
\end{abstract}

Keywords : droplet diameter, SMD, biodiesel

18 Surya, I Gede Teddy Prananda; Simulasi Numerik Ii : Distribusi Diameter Droplet Pada Semprotan Biodiesel Kelapa, Jatropa Curcas Dan Minyak Goreng Bekas Dalam Ruang Bakar Mexican Hat 


\section{PENDAHULUAN}

Biodiesel merupakan sumber energi alternatif yang dapat digunakan untuk mengurangi ketergantungan terhadap bahan bakar fosil yang persediaannya semakin terbatas. Keunggulan lain dari biodiesel adalah bahan bakar ini ramah lingkungan karena diproduksi dari hewan atau tumbuhan dan pengembangan bahan bakar nabati di beberapa negara dilakukan menggunakan tanaman lokal sebagai feedstock [[1],[2]]. Indonesia dengan sumber daya alam melimpah memiliki beberapa sumber bahan baku biodiesel antara lain kelapa, jatropa curcas bahkan minyak goreng bekas. Melalui proses esterifikasi atau transesterifikasi yang tepat maka biodiesel tersebut dapat memiliki properties menyerupai diesel fuel.

Nilai kalor dalam biodiesel lebih kecil daripada diesel fuel sedangkan viskositas biodiesel umumnya melebihi viskositas diesel fuel sehingga diperlukan penelitian lanjut mengenai karakteristik semprotannya agar proses pembakaran berlangsung sempurna. Proses atomisasi semprotan full cone pada sac nozzle dijelaskan Baumgarten [[3]]. Ketika meninggalkan nozzle, jet mulai breakup membentuk semprotan yang bersudut. Primary breakup adalah breakup pada awal semprotan dan menghasilkan ligamen serta droplet yang membentuk dense spray sekitar nozzle. Pada injeksi tekanan tinggi, kavitasi dan turbulen dalam lubang injeksi adalah penyebab awal mekanisme breakup. Perbedaan kecepatan relatif antara droplet dan gas akan menimbulkan gaya aerodinamik yang dapat memperlambat laju droplet dan menyebabkan droplet pecah menjadi lebih kecil, peristiwa ini dinamakan secondary breakup. Droplet sekitar spray tip memiliki gaya drag paling besar dan kecepatannya lebih lambat daripada droplet dalam area wake sedangkan droplet dengan energi kinetik rendah didorong ke arah radial dan membentuk semprotan bagian terluar hingga membentuk sudut semprotan. Fasa liquid banyak terdapat di sekitar sumbu semprotan daripada di bagian luar semprotan, kecepatan droplet tertinggi berada pada daerah sumbu dan berkurang ke arah radial akibat interaksi droplet dengan gas. Dense spray memiliki peluang sangat besar untuk collision yang dapat menyebabkan kecepatan dan ukuran droplet berubah menjadi lebih kecil atau bergabung menjadi besar yang biasa disebut coalescence.

Ketika biodiesel disemprotkan dalam ruang bakar maka akan terbentuk droplet dan berukuran besar akan mengalami breakup. Hal ini sangat penting untuk membentuk semprotan yang sempurna. Azzopardi [[4]] telah melakukan eksperimen menggunakan kamera kecepatan tinggi. Hasil eksperimen menunjukkan hal menarik bahwa mekanisme breakup tidak sama pada setiap angka Weber. Angka Weber rendah menyebabkan droplet tipis pada bagian tengah lalu pecah dimulai dari bagian tersebut sedangkan pada Weber tinggi breakup dimulai dari tepi droplet. Hwang dkk [[5]] melakukan eksperimen untuk mempelajari karakteristik semprotan seperti sudut semprotan, penetrasi spray tip dan SMD. Menggunakan injektor berdiameter $0,2,0,3,0,4 \mathrm{~mm}$. tekanan injeksi yang digunakan $35 \mathrm{Mpa}$ dan tekanan udara yang digunakan $0,6,0,1,1,5 \mathrm{Mpa}$. Dalam penelitian ini diketahui bahwa kenaikan tekanan gas menyebabkan sudut semprotan bertambah dan mengurangi penetrasi. Hasil eksperimen ini dibandingkan dengan teori dan hasil eksperimen peneliti lainnya dan menunjukkan hasil yang serupa yaitu kenaikan tekanan ambient dan diameter nozzle meningkatkan SMD pada arah downstream. Penetrasi spray tip ini merupakan faktor penting untuk menentukan desain ruang bakar sebuah motor diesel.

Metoda Sauter Mean Diameter digunakan untuk perhitungan ukuran droplet rata-rata. Didefinisikan sebagai diameter droplet yang mempunyai volume sama dengan rasio luas permukaannya pada keseluruhan semprotan.

$S M D=\frac{\sum n D^{3}}{\sum n D^{2}}$

Ukuran butiran-butiran droplet yang dihasilkan oleh semprotan selalu berbeda untuk setiap jenis biodiesel. Ukuran droplet rata-rata tergantung dari properti biodiesel berupa tegangan permukaan, densitas dan viskositas cairan serta parameter injeksi berupa laju aliran massa, tekanan injeksi dan tekanan gas. Interaksi semprotan dengan dinding telah dipelajari oleh Alloca dkk [[6]] melalui eksperimen terhadap injeksi tekanan tinggi pada pelat datar berjarak $20 \mathrm{~mm}$ dari nozzle dan kondisi tekanan atmosfir serta temperatur ambient telah diteliti menggunakan stroboflash-CCD camera. Bahan bakar yang digunakan dalam penelitian ini adalah ISO 4112 dengan viskositas $2,5 \mathrm{cst}$ pada temperatur $40^{\circ} \mathrm{C}$ dan tegangan permukaan $0.0284 \mathrm{~N} / \mathrm{m}$ pada temperatur 80 ${ }^{\circ} \mathrm{C}$.

Menurut Naber dan Farell [[7]], regim tumbukan didasarkan atas angka Weber, dimana untuk angka Weber>130 tumbukan akan berada pada regim splash sedangkan angka Weber $<130$ menunjukkan tumbukan akan berada pada regim spread. Regim spread adalah suatu kondisi tumbukan dimana droplet dalam semprotan akan meluncur dipermukaan dinding dan menjauh dari lokasi tumbukan hingga energi kinetiknya habis. Sedangkan regim splash adalah kondisi tumbukan dimana droplet akan pecah dan memantul setelah menumbuk

19 Surya, I Gede Teddy Prananda; Simulasi Numerik Ii : Distribusi Diameter Droplet Pada Semprotan Biodiesel Kelapa, Jatropa Curcas Dan Minyak Goreng Bekas Dalam Ruang Bakar Mexican Hat 
dinding sehingga terbentuk butiran-butiran dengan ukuran yang lebih kecil.

$$
W e_{i m p}=\frac{\rho V_{i m p}^{2} d}{\sigma}
$$

Beberapa eksperimen menjelaskan bahwa proses penyemprotan bahan bakar sangat penting dalam motor diesel, proses ini mencakup atomisasi, collision, coalescence dan breakup, momentum, energi dan interaksi droplet dengan dinding. Karakteristik semprotan bahan bakar dipengaruhi oleh beragam parameter dan memiliki proses cukup rumit. Untuk mengetahui semprotan bahan bakar lebih rinci maka diperlukan bantuan CFD. Validasi eksperimen dan numerik dilakukan oleh Reitz dan Rutland [[8]] dalam penelitian menggunakan motor diesel silinder tunggal Caterpillar 3406. Tipe piston yang digunakan adalah Mexican Hat berdiameter $137,19 \mathrm{~mm}$ dan pemodelan KIVA menggunakan submodel untuk mempelajari karakteristik semprotan hingga gas sisa pembakaran. Hasil penelitian menunjukkan bahwa pemodelan turbulensi yang tepat adalah RNG k- $\varepsilon$ karena dapat memprediksi struktur large-scale yang terbentuk oleh gerakan squish dan spray.

Pemodelan numerik untuk mempelajari panjang break-up dan ukuran droplet pada dua tipe pressure-swirl atomizer yang bekerja dalam tekanan ambient dilakukan oleh Senecal dkk [[9]] dengan bantuan software KIVA-3V. Dalam penelitian ini persamaan Rosin-Ramler digunakan untuk perhitungan distribusi diameter droplet, persamaan Lagrangian untuk perhitungan jejak droplet dan setiap droplet diasumsikan memiliki propertis kinematik dan termodinamika yang sama. Droplet collision dan coalescene diselesaikan menggunakan persamaan O'Rourke dan secondary breakup menggunakan Taylor Analogy Breakup (TAB) sedangkan persamaan fasa gas menggunakan algoritma Lagrangian-Eulerian (ALE). Fluida kerja yang digunakan adalah Stoddard Solvent sebanyak 14 dan $44 \mathrm{mg}$. Hasil numerik dari kedua jenis injektor ini serupa dengan eksperimen sebelumnya dan menunjukkan linear stability analysis dalam pemodelan pressure swirl atomizer dipengaruhi oleh udara dalam chamber, tegangan permukaan dan viskositas bahan bakar serta persamaan yang digunakan dalam KIVA-3V tersebut dapat memprediksi penetrasi semprotan, SMD dan visualisasi dengan akurat.

Dalam atomisasi bahan bakar menggunakan pressure-swirl atomizer, interaksi antara injektor dengan semprotan bahan bakar merupakan hal yang penting. Schmidt dkk [[10]] memberikan penjelasan akurat mengenai hal tersebut melalui pemodelan yang dikenal dengan nama Linearized Instability Atomization (LISA) yang bertujuan sebagai prediksi bentuk semprotan dekat nozzle tip. LISA memiliki tiga tahap, yaitu pembentukan film, lapisan tipis dan atomisasi. Pemodelan ini diterapkan untuk mempelajari penetrasi, sudut, flux massa dan visualisasi semprotan pressure-swirl injector berdiameter 560 um dan 458 um yang bekerja dalam ambient pressure dengan pasokan bahan bakar 56.8; 20 dan $69 \mathrm{~mm} 3$. Dengan menggunakan TAB sebagai pemodelan secondary breakup, RNG k- $\varepsilon$ sebagai pemodelan turbulen dan collision serta coalescence diselesaikan menggunakan metoda O'Rourke. Proses semprotan ini diselesaikan secara transient dan membuktikan bahwa prediksi numerik sesuai dengan hasil eksperimen, droplet pada awal injeksi berukuran besar sedangkan pada akhir injeksi terjadi perbedaan antara numerik dan eksperimen yang disebabkan karena injector closing tidak dapat diselesaikan dalam kasus transient.

\section{METODOLOGI}

Bahan bakar yang digunakan pada penelitian ini adalah biodiesel Kelapa, Jatropa Curcas dan Minyak Goreng Bekas, Tabel 1. Bahan bakar ini diinjeksikan menggunakan nozzle berdiameter 0,22 mm dengan laju massa bahan bakar 5,9 gr/s. Pada simulasi menggunakan FLUENT 6.2 ini tekanan injeksi yang digunakan adalah 200 bar sedangkan tekanan ruang bakar 6 bar.

Tabel 1 Hasil pengujian bahan bakar di PT. Pertamina Surabaya 2006

\begin{tabular}{|l|c|c|c|c|c|c|}
\hline & & \multirow{2}{*}{$\begin{array}{c}\text { ASTM } \\
\text { Propertis }\end{array}$} & Sat & $\begin{array}{c}\text { Dest } \\
\text { Method }\end{array}$ & Diesel & \multicolumn{3}{|c|}{ Hasil Pengujian Biodiesel } \\
\cline { 5 - 7 } & & Kelapa & J.C. & MGB \\
\hline $\begin{array}{l}\text { Density at } \\
15^{\circ} \mathrm{C}\end{array}$ & $\mathrm{kg} / \mathrm{m}^{3}$ & $\mathrm{D} 1299$ & 863 & 880.4 & 906.6 & 915.2 \\
\hline $\begin{array}{l}\text { Kinematic } \\
\text { Viscosity } \\
\text { at } 40^{\circ} \mathrm{C}\end{array}$ & $\mathrm{mm}^{2} / \mathrm{s}$ & $\mathrm{D} 445$ & 3.694 & 7.78 & 17.85 & 37.53 \\
\hline $\begin{array}{l}\text { Tegangan } \\
\begin{array}{l}\text { Permukaa } \\
\text { n }\end{array}\end{array}$ & $\mathrm{N} / \mathrm{m}^{2}$ & --- & - & 0.0621 & 0.0699 & 0.073 \\
\hline
\end{tabular}

Tipe ruang bakar yang digunakan adalah submodel Mexican Hat dengan nozzle-dinding berjarak 58,4 mm. Ruang bakar ini umumnya digunakan pada motor diesel putaran rendah dengan daya yang besar.

20 Surya, I Gede Teddy Prananda; Simulasi Numerik Ii : Distribusi Diameter Droplet Pada Semprotan Biodiesel Kelapa, Jatropa Curcas Dan Minyak Goreng Bekas Dalam Ruang Bakar Mexican Hat 


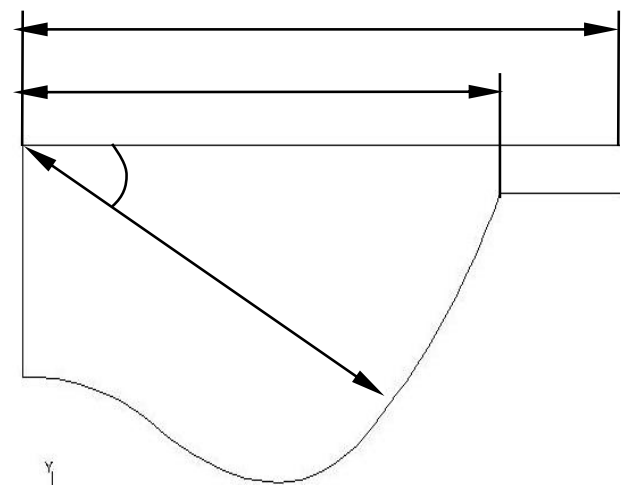

Gambar 1 Pemodelan ruang bakar tipe Mexican Hat

\section{HASIL DAN PEMBAHASAN}

Sauter Mean Diameter merupakan metoda yang digunakan untuk menentukan diameter droplet rata-rata. Semakin kecil tegangan permukaan maka biodiesel tersebut akan memiliki droplet berdiameter kecil karena tegangan permukaan berguna untuk mempertahankan bentuk droplet mengatasi gaya drag saat bergesekan dengan udara dan diameter tersebut semakin berkurang sepanjang arah penetrasi akibat bergesekan dengan udara, gambar 3. Pada jarak penetrasi 0 hingga $40 \mathrm{~mm}$ terjadi fluktuasi perubahan diameter droplet yang disebabkan oleh collision dan coalescence antar droplet tersebut. Pada penelitian ini biodiesel Kelapa memiliki SMD terkecil 67,1 hingga $80,1 \mu \mathrm{m}$. Hal ini terjadi karena biodiesel tersebut memiliki tegangan permukaan $0.0621 \mathrm{~N} / \mathrm{m}^{2}$, lebih kecil daripada Jatropa curcas dan Minyak Goreng Bekas.

Perilaku semprotan menumbuk dinding pada umumnya dipengaruhi oleh ukuran droplet, kecepatan tumbukan dan kondisi permukaan dinding. Parameter tak berdimensi yang menentukan jenis tumbukan adalah Weber Number. Gambar 4, 5, 6 menunjukkan bahwa biodiesel Kelapa, Jatropa curcas dan Minyak Goreng Bekas dengan jarak nozzle tipdinding $58,4 \mathrm{~mm}$ memiliki regim tumbukan yang beragam. Dengan menggunakan persamaan (2) diketahui bahwa Kelapa memiliki angka Weber 125,6, Jatropa Curcas 107,2 dan Minyak Goreng Bekas 148,5. Hal ini menunjukkan bahwa pada semprotan dengan tekanan injeksi 200 bar dan tekanan ruang bakar 6 bar hanya Minyak Goreng Bekas yang memiliki regim splash karena angka Weber $>130$.

Berdasarkan Naber dan Farel [[7]], biodiesel Minyak Goreng Bekas dapat membentuk regim splash sementara biodiesel lainnya hanya memiliki regim spread. Dengan demikian semakin tinggi tekanan injeksi, regim tumbukan semakin cenderung ke regim splash. Fenomena regim tumbukan dari ketiga biodiesel terjadi karena biodiesel Minyak Goreng Bekas memiliki densitas besar $915,2 \mathrm{~kg} / \mathrm{m}^{3}$ dan tegangan permukaan yang tinggi $0,072 \mathrm{~N} / \mathrm{m}^{2}$ dimana tegangan permukaan tersebut mempertahankan bentuk droplet agar tidak breakup saat bergesekan dengan udara.

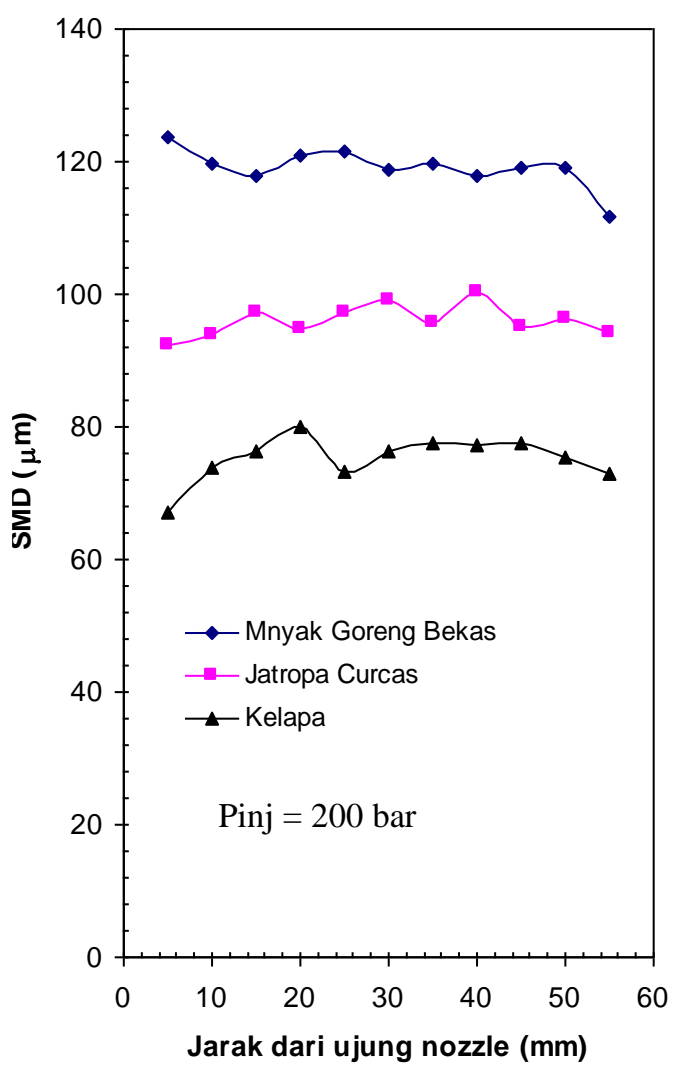

\section{Gambar 2 Distribusi diameter droplet pada semprotan biodiesel}

Gambar 3, 4 dan 5 membuktikan bahwa biodiesel dengan viskositas besar menyebabkan jarak penetrasi lebih jauh karena droplet memiliki tegangan permukaan lebih besar. Biodiesel Kelapa memiliki jarak penetrasi terpendek karena dropletnya mudah breakup dan sudut semprotan menjadi lebih besar karena droplet di tepi semprotan memiliki energi lebih kecil dan mengalami mengalami breakup lebih cepat. Dengan penjelasan mengenai regim tumbukan pada ketiga jenis biodiesel ini, dapat dipahami bahwa regim tumbukan splash yang diciptakan biodiesel Minyak Goreng Bekas sangat baik untuk tipe ruang bakar Mexican Hat. Regim splash ini sangat menguntungkan bagi proses atomisasi lanjutan 
setelah menumbuk dinding, sehingga proses pembakaran berlangsung lebih baik.
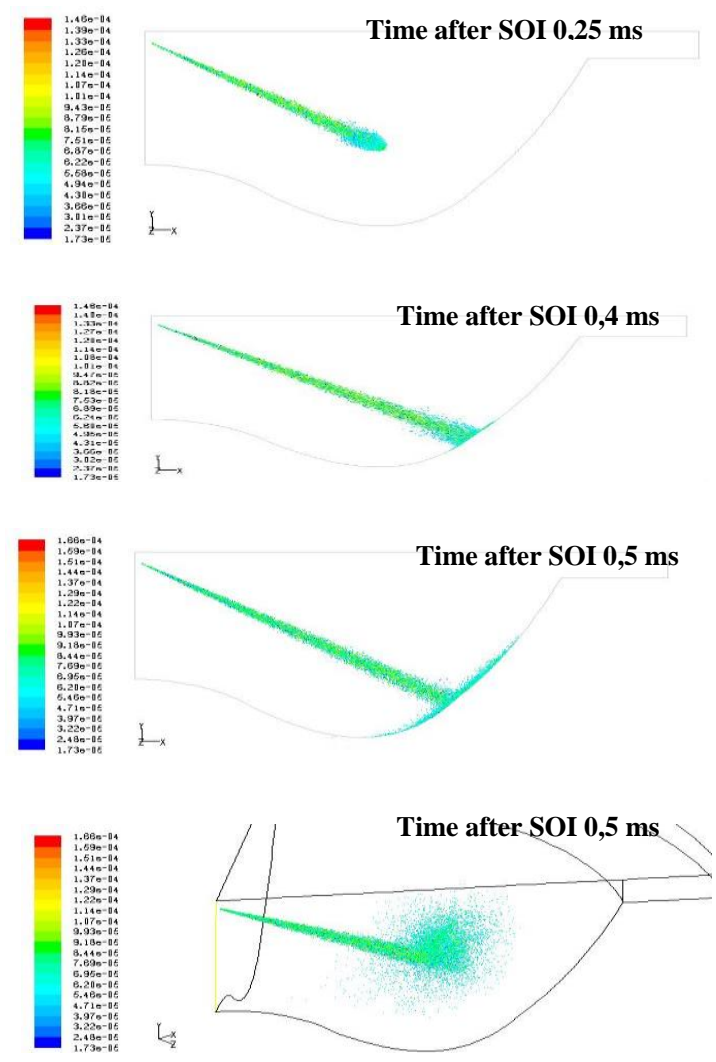

Gambar 3 Visualisasi droplet pada biodiesel Kelapa

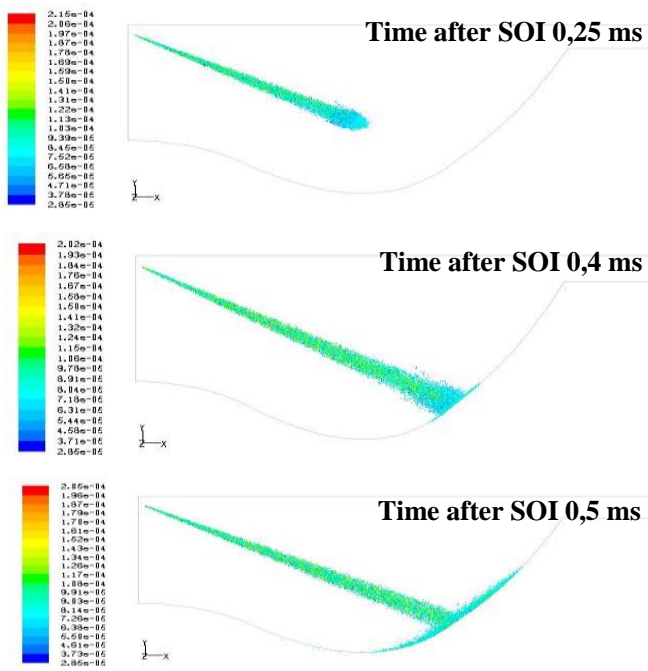

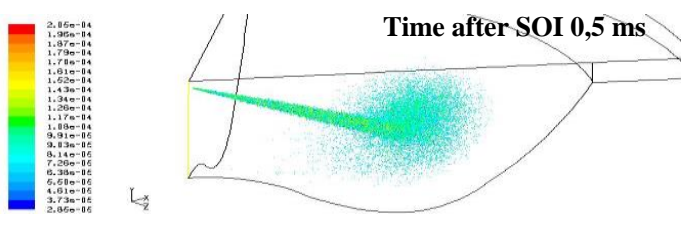

\section{Gambar 4 Visualisasi droplet pada biodiesel Jatropa Curcas}
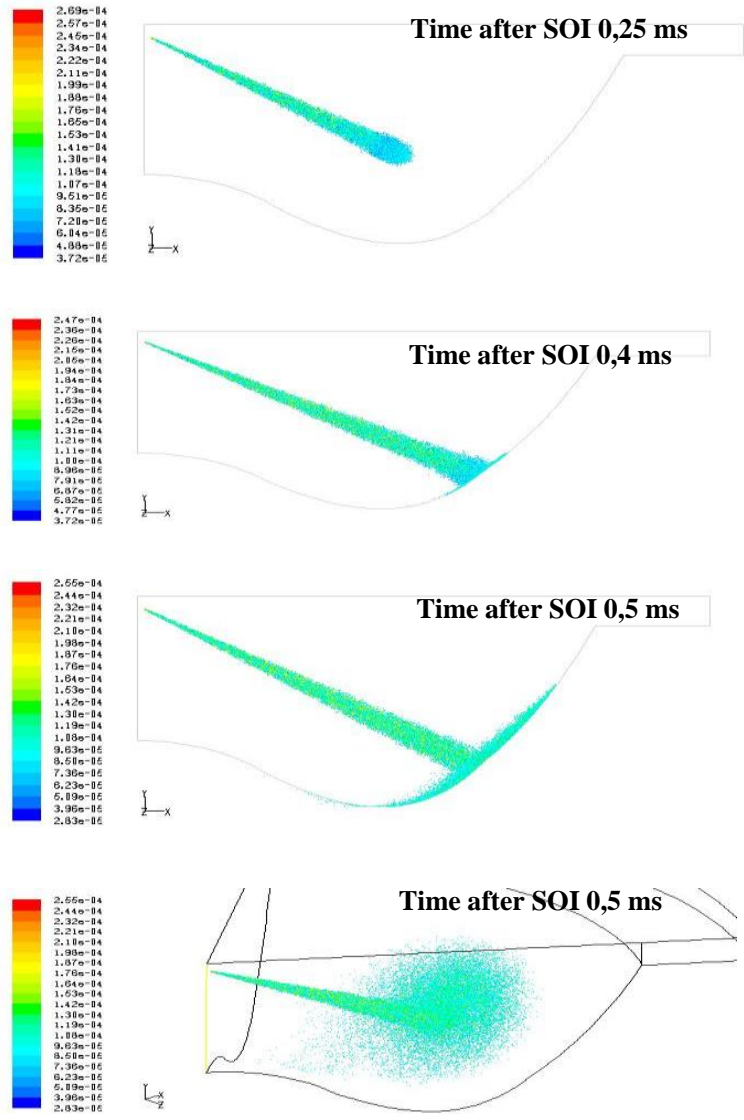

\section{Gambar 5 Visualisasi droplet pada biodiesel Minyak Goreng Bekas}

\section{KESIMPULAN}

Minyak Goreng Bekas merupakan sumber bahan baku biodiesel yang baik untuk motor diesel putaran rendah karena memiliki viskositas dan tegangan permukaan yang dapat menghasilkan regim splash saat menumbuk dinding piston. Proses semprotan biodiesel pada arah downstream akan mengami collision membentuk droplet berdiameter lebih kecil atau coalescence sehingga droplet berdiameter besar. Proses ini tidak sama pada setiap biodiesel sehingga setiap semprotan biodiesel memiliki karakteristik penetrasi, sudut atau diameter 
droplet beragam. Penelitian lebih lanjut mengenai biodiesel Kelapa dan Jatropa Curcas dapat dilakukan pada motor diesel putaran tinggi yang menggunakan regim spread untuk mengawali pembakaran.

\section{DAFTAR PUSTAKA}

[1] Saydut, A., Duz, M. Z., Kaya, C., Kafadar, A. B. dan Hamamci, C., "Transesterified Sesame (Sesamum Indicum L.) Seed Oil as a Biodiesel Fuel”, Bioresource Technology Vol. 99, hal. 6656-6660, 2008.

[2] Sun, H., Ding, Y., Duan, J., Zhang, Q., Wang, Z., Lou, H. dan Zheng, X., "Transesterification of Sunflower Oil to Biodiesel on $\mathrm{ZrO} 2$ Supported La2O3 Catalyst", Bioresource Technology Vol. 101, hal 953-958, 2010.

[3] Baumgarten, C.,'Mixture Formation in Internal Combustion Engines", Springer-Verlag Berlin Heidelberg, Germany, 2006.

[4] Azzopardi, B. J.,"Atomization Fundamentals," Department of Chemical Engineering, University of Nottingham, 1991.
[5] Hwang, J.S., HA, J.S. dan No, S. Y.,"Spray Characteristics of DME in Conditions of Common Rail Injection System", International Journal of Automotive Technology, Vol. 4, No.3 hal. 119, 2003.

[6] Alloca, L., Amato, U., Bertoli, C. dan Corcione, F. E., "Comparison of Models and Experiments for Diesel Fuel Sprays", International Syposium COMODIA90:255-261, 1990.

[7] Naber, J. D. dan Reitz, R. D.,'Modeling Engine Spray/Wall Impingement", SAE 88107, 1988.

[8] Reitz, R. D. dan Rutland, C. J.,'Development and Testing of Diesel Engine CFD Models", Prq Energy Cumhusr. Sri. Vol. 21, hal. 173-196, 1995.

[9] Senecal, P.K., Schmidt, D.P., Nouar, I., Rutland, C.J., Reitz, R.D. dan Corradin, M.L.,"Modeling high-speed viscous liquid sheet atomization",International Journal of Multiphase Flow, Vol. 25, hal.1073-1097, 1999.

[10]Schmidt, D.P., Nouar, I., Senecal, P.K., Rutland, C.J., Martin, J. K. dan Reitz, R.D.,'PressureSwirl Atomization in the Near Field", SAE 199901-0496, 1999. 